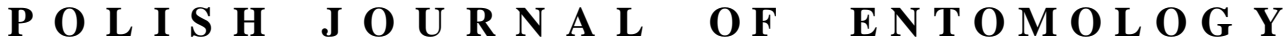

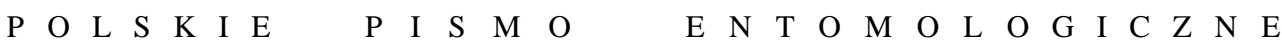

VOL. 87: 141-151

Lublin

30 June 2018

DOI: $10.2478 /$ pjen-2018-0010

\section{Preliminary research on mortality of wood destroying Anobiidae \\ (Coleoptera) following the application of p-dichlorobenzene in combination with low oxygen atmosphere fumigation}

\author{
ALEKSANDRA WÓJCIK, ADAM KRAJEWSKI \\ Department of Wood Science and Wood Protection, University of Life Sciences - Szkoła \\ Główna Gospodarstwa Wiejskiego w Warszawie, ul. Nowoursynowska 159, \\ 02-787 Warszawa, Poland
}

\begin{abstract}
Experiments were undertaken in connection with the need, indicated in the literature, for the proper choice of a substance enhancing the effect of a low oxygen atmosphere used as a means of controlling wood boring insects in museum collections and historical objects. A low oxygen atmosphere itself causes the death of wood boring insects after a relatively long period of application. Thus, attempts were made to use p-dichlorobenzene to accelerate the effects of a low oxygen atmosphere in the control of wood boring insects. The experiments were performed as a continuation of preliminary research on the effect of p-dichlorobenzene on Anobiidae in an aerobic atmosphere. The paper present the results of gassing Anobium punctatum and Ptilinus pectinicornis (Coleoptera: Anobiidae) larvae with 1,4-dichlorobenzene in a low oxygen atmosphere of nitrogen and argon. The experiments were performed in laboratory conditions at a temperature of $20^{\circ} \mathrm{C}$ on larvae extracted from wood. The results do not show a faster elimination of larvae of either species using p-dichlorobenzene in a low oxygen atmosphere as compared to using p-dichlorobenzene in an aerobic atmosphere. Complete eradication of larvae in the test groups was obtained after 48 hours when using p-dichlorobenzene in nitrogen. The results obtained when using p-dichlorobenzene in argon appear to be worse at fumigation times shorter than 48 hours.
\end{abstract}

KEY WORDS: fumigation of wood, p-dichlorobenzene, anoxia, wood boring insects, Anobiidae.

\footnotetext{
* Corresponding author: adam_krajewski@sggw.pl
} 


\section{INTRODUCTION}

The list of toxic gases applicable to wood disinfestation has recently been reduced, especially since methyl bromide was withdrawn from use in Germany in 2002 and in the European Union in 2005 (KREHAN 2002). For controlling wood boring insects in museum collections, the popularity of the low oxygen atmosphere method has been growing (VAlentin 1990, VAlentin \& Preusser 1990a, 1990b, Reichmuth et al. 1991, Considine et al. 1993, KoestLer 1993, 1996, RUST \& KenNedy 1993, KoestLer \& MATHEws 1994, Brokerhof 1999, Koestler et al. 2000, Unger \& UNGER 1995, HASEGAWA 2001, BINKER et al. 2001, KigaWA et al. 2003). Because of the very slow effect of a low oxygen atmosphere, however, attempts have been Made to use toxic substances, such as p-dichlorobenzene, in order to accelerate the process (KIGAWA \& YAMANO 1996). The present research examines this idea.

The wood of museum exhibits and historical objects is often attacked by insects from the Anobiidae family. The effectiveness of using p-dichlorobenzene as a means of controlling wood boring insects, however, has been relatively poorly examined (WóJCIK et al. 2014). P-dichlorobenzene has so far been utilised mostly for the disinfestation of fabrics attacked by insects of the Tineidae (Lepidoptera) and Dermestidae (Coleoptera) families (REGAN 1982). This chemical compound is contained in preparations designed for fabric disinfestation such as Paracide, Paradow and Fumigant 1 (UNGER 1988). Research into the possible utilisation of p-dichlorobenzene in combination with a low oxygen atmosphere as a means of accelerating Anobiidae control was performed at the Department of Wood Science and Wood Protection (Faculty of Wood Technology, University of Life Sciences SGGW), as a continuation of research into the effects of $\mathrm{p}$-dichlorobenzene in an aerobic atmosphere (WóJCIK et al. 2014).

\section{MATERIALS AND METHODOLOGY}

Nitrogen and argon of technical purity together with 1,4-dichlorobenzene $\left(\mathrm{C}_{6} \mathrm{H}_{4} \mathrm{Cl}_{2}\right)$ (Fluka) were used in the experiments. The gassing of biological material using pdichlorobenzene in combination with a low oxygen atmosphere took place in one-litre desiccators with T-joints, each mounted with two multipath taps, sealed with silicone vacuum grease (GE Bayer Silicones). Each tap was joined by rubber tubes to steel bottles containing nitrogen or argon of technical purity. Each variant of the experiment a different combination of duration, type of non-reactive gas and species of insect - was performed in a separate desiccator. This enabled the content of p-dichlorobenzene in the gas mixture at the end of the experiment to be measured. 
Solid p-dichlorobenzene was placed on $55 \mathrm{~mm}$ diameter Petri dishes in a glass desiccator, covered with a glass lid and sealed with silicone. The p-dichlorobenzene samples were weighed before and after fumigation on a Radwag-WSP laboratory scale, accurate to $0.01 \mathrm{~g}$, in order to calculate the amount of the substance sublimed.

At the beginning of each variant of the experiment, oxygen was removed from the desiccators using an ILMVAC MPC $052 \mathrm{Z}$ diaphragm pump and flushed three times with technically pure nitrogen or argon. The oxygen content during fumigation was monitored using a Heavy Duty Dissolved Oxygen Meteor (model 407510) oxygen meter (Extech). The oxygen content achieved in this way ranged from $0.3 \%$ to $1 \%$ at the end of the experiment.

Experiments on the effects of p-dichlorobenzene in nitrogen and argon were carried out at a temperature of $20^{\circ} \mathrm{C}$ on mature larvae of Anobium punctatum (DE GEER, 1774) and Ptilinus pectinicornis (LinNAEUS, 1758) (Coleoptera: Anobiidae). The insects were extracted from breeding blocks and weighed. Individual masses ranged from 0.02 to 0.04 $\mathrm{g}$ (av. $0.03 \mathrm{~g}$ ). Each of the three series of experiments included a control variant. In each control 20 larvae were placed outside the wood in an aerobic atmosphere for 48 hours at $20^{\circ} \mathrm{C}$ and a relative humidity of $55 \%$. The experimental variants are listed in Table 1.

Table 1. Variants of experiments and numbers of Anobiidae larvae in applications of p-dichlorobenzene to low oxygen atmosphere fumigation at a temperature of $20^{\circ} \mathrm{C}$.

\begin{tabular}{|c|c|c|c|c|c|c|}
\hline \multirow[t]{2}{*}{ Atmosphere } & \multicolumn{6}{|c|}{ Times } \\
\hline & $\mathbf{0 ~ h}$ & $3 \mathrm{~h}$ & $6 \mathrm{~h}$ & $18 \mathrm{~h}$ & $24 \mathrm{~h}$ & $48 \mathrm{~h}$ \\
\hline \multicolumn{7}{|c|}{ Anobium punctatum } \\
\hline Nitrogen & 20 larvae & 20 larvae & 24 larvae & 22 larvae & 20 larvae & 20 larvae \\
\hline \multicolumn{7}{|c|}{ Ptilinus pectinicornis } \\
\hline Nitrogen & 20 larvae & 20 larvae & - & 22 larvae & 20 larvae & 20 larvae \\
\hline \multicolumn{7}{|c|}{ Ptilinus pectinicornis } \\
\hline Argon & 20 larvae & - & - & 20 larvae & 20 larvae & 20 larvae \\
\hline
\end{tabular}

The $20^{\circ} \mathrm{C}$ ambient temperature in the laboratory was obtained by appropriately setting the air conditioning system. It was controlled in the room and in the desiccators using disc thermometers (Cole Palmer). The humidity of the gases in the laboratory and in the containers used for breeding the wood boring insects was monitored with TA 100 thermohygrometers (TFA). 
The mortality rate of the larvae in each variant of the experiment was estimated as follows. After the time for implementing a given variant of the experiment had elapsed, atmospheric air was introduced and the larvae were removed from the desiccator, isolated and counted. Larvae were considered dead if they did not move at all when irritated, and also displayed signs of colour change and a complete lack of body turgor. Definitely dead individuals were then removed, while larvae showing evident signs of life (movement), as well as those potentially still alive (no colour change, no lack of skin shell tension) were placed in holes drilled in sapwood Scots pine (Pinus sylvestris L.) blocks $15 \times 25 \times 50 \mathrm{~mm}$ in size. The diameters of the holes were adjusted to the size of the individual larvae. These were regarded as living only if after another 30 days they were able to bite into deeper layers of the wood of their own accord. Individuals that had survived the gassing process were treated as being alive, while those that had failed to bite into the wood were regarded as dead. Based on these calculations, the mortality rate of the larvae in the given variant of the experiment was determined.

Chebyshev's inequality was used to evaluate the significance of the mortality in each variant of the experiment. If the absolute difference between the average arithmetic values of mortality of both insect species in a given variant (insect / time / medium) was greater than or equal to three times the standard error of the difference, i.e.,

$$
\left|\overline{x_{1}}-\overline{x_{2}}\right| \geq 3 \times \varepsilon\left(\overline{x_{1}}-\overline{x_{2}}\right)
$$

then the difference between the averages was taken to be statistically significant. Otherwise, it was treated as accidental.

\section{RESULTS}

The mortality rates of Anobium punctatum and Ptilinus pectinicornis larvae following application of p-dichlorobenzene to low oxygen atmosphere fumigation at a temperature of $20^{\circ} \mathrm{C}$ are given in Table 2 .

In order to simplify the comparison, the results are shown in Fig. 1 together with the mortality rates of both species gassed with p-dichlorobenzene in an aerobic atmosphere, described in detail in an earlier paper (WóJCIK et al. 2014).

The results of the statistical analysis of the differences in mortality between Anobium punctatum and Ptilinus pectinicornis larvae following application of $\mathrm{p}$-dichlorobenzene to low oxygen atmosphere fumigation are shown in Table 3. 
Table 2. Mortality of Anobium punctatum and Ptilinus pectinicornis following application of p-dichlorobenzene to low oxygen atmosphere fumigation at a temperature of $20^{\circ} \mathrm{C}$. FumT - fumigation time; PDC - content of p-dichlorobenzene in a nitrogen atmosphere at the end of the experiment; MortA - mortality of Anobium punctatum larvae in a nitrogen atmosphere; MortP1 - mortality of Ptilinus pectinicornis larvae in a nitrogen atmosphere; MortP2 - mortality of Ptilinus pectinicornis larvae in a, argon atmosphere.

\begin{tabular}{ccccccc}
\hline $\begin{array}{c}\text { FumT } \\
{[\mathrm{h}]}\end{array}$ & $\begin{array}{c}\text { PDC } \\
{\left[\mathrm{g} \cdot \mathrm{dm}^{-3}\right]}\end{array}$ & $\begin{array}{c}\text { MortA } \\
{[\%]}\end{array}$ & $\begin{array}{c}\text { PDC } \\
{\left[\mathrm{g} \cdot \mathrm{dm}^{-3}\right]}\end{array}$ & $\begin{array}{c}\text { MortP1 } \\
{[\%]}\end{array}$ & $\begin{array}{c}\text { PDC } \\
{\left[\mathrm{g} \cdot \mathrm{dm}^{-3}\right]}\end{array}$ & $\begin{array}{c}\text { MortP2 } \\
{[\%]}\end{array}$ \\
\hline 0 & 0 & $\mathbf{1 5}$ & 0 & $\mathbf{1 0}$ & - & - \\
3 & 23 & $\mathbf{3 0}$ & 30 & $\mathbf{3 0}$ & - & - \\
6 & 23 & $\mathbf{4 5}$ & - & - & - & - \\
18 & 76 & $\mathbf{5 5}$ & 79 & $\mathbf{5 0}$ & 17 & $\mathbf{2 0}$ \\
24 & 80 & $\mathbf{6 0}$ & 82 & $\mathbf{9 5}$ & 20 & $\mathbf{4 5}$ \\
48 & 92 & $\mathbf{1 0 0}$ & 90 & $\mathbf{1 0 0}$ & 80 & $\mathbf{8 0}$ \\
\hline
\end{tabular}

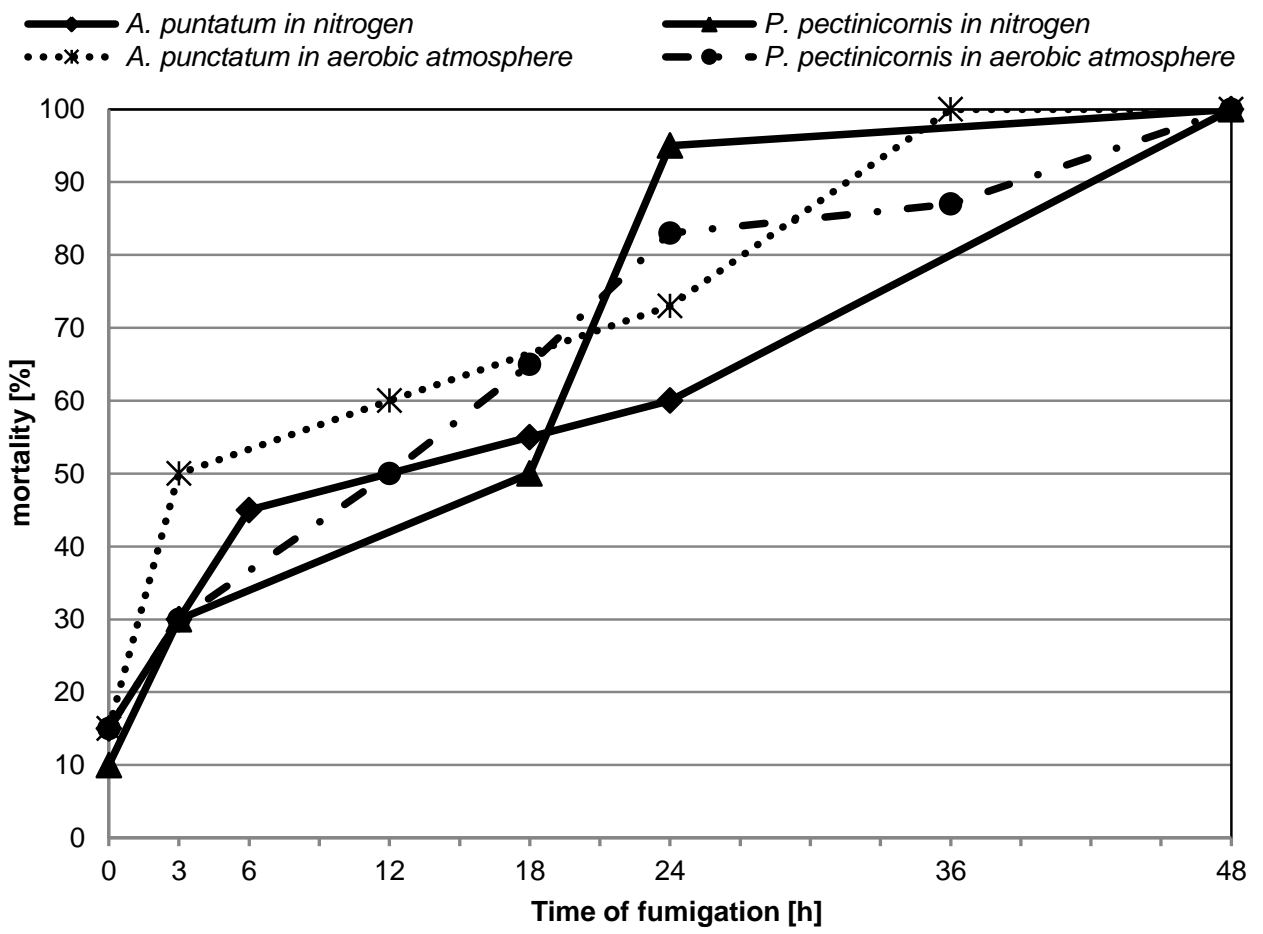

Fig. 1. The mortality of Anobium punctatum and Ptilinus pectinicornis larvae gassed with p-dichlorobenzene in nitrogen or oxygen atmosphere at $20^{\circ} \mathrm{C}$, together with earlier results of the application of p-dichlorobenzene in an aerobic atmosphere at $20^{\circ} \mathrm{C}$ (WÓJCIK et al. 2014). 
Table 3. Statistical analysis of the differences in mortality between Anobium punctatum and Ptilinus pectinicornis larvae following application of $\mathrm{p}$-dichlorobenzene to low oxygen atmosphere fumigation at a temperature of $20^{\circ} \mathrm{C}$.

\begin{tabular}{ccl}
\hline Times & $\left|\overline{x_{1}}-\overline{x_{2}}\right| \geq 3 \cdot \varepsilon\left(\overline{x_{1}}-\overline{x_{2}}\right)$ & Statistical analysis of the results of the experiment \\
\hline $0 \mathrm{~h}$ & $0.05<0.321$ & Statistically insignificant difference in mortality rates \\
$3 \mathrm{~h}$ & $0<0.446$ & Statistically insignificant difference in mortality rates \\
$18 \mathrm{~h}$ & $0.05<0.462$ & Statistically insignificant difference in mortality rates \\
$24 \mathrm{~h}$ & $0.35<0.369$ & Statistically insignificant difference in mortality rates \\
\hline
\end{tabular}

In the control variants, mortality rates of the larvae of each species were low, and the difference between them was statistically insignificant. In each fumigation variant of the same duration (except for the 24-hour variant) the differences between the mortality rates of both species were also small and statistically insignificant. The results of the statistical analysis of the significance of differences in mortality rates of a given species for different durations of applying p-dichlorobenzene to low oxygen atmosphere fumigation at $20^{\circ} \mathrm{C}$ are shown in Table 4.

Table 4. Statistical analysis of the significance of differences in mortality rates of each species for different durations of applying p-dichlorobenzene to low oxygen atmosphere fumigation at $20^{\circ} \mathrm{C}$. Comp. - compared variants; $\mathrm{Ap}$ - Anobium punctatum; $\mathrm{Pp}-$ Ptilinus pectinicornis; * statistically significant difference; ${ }^{*}$ statistically insignificant difference.

\begin{tabular}{cccc}
\hline $\begin{array}{c}\text { Comparison of mortality } \\
\text { in variants: }\end{array}$ & $\begin{array}{c}\text { Beetle species and the atmosphere (medium) in which } \\
\text { it was fumigated with p-dichlorobenzene } \\
\left|\overline{x_{1}}-\overline{x_{2}}\right| \geq 3 \cdot \varepsilon\left(\overline{x_{1}}-\overline{x_{2}}\right)\end{array}$ \\
\cline { 2 - 4 } & $\boldsymbol{A p}-$ nitrogen & $\boldsymbol{P p}-$ nitrogen & $\boldsymbol{P p}$ - argon \\
\hline $0 \mathrm{~h}-18 \mathrm{~h}$ & $0.4<0.415^{\#}$ & $0.4>0.396^{*}$ & $0.1<0.344^{\#}$ \\
$0 \mathrm{~h}-24 \mathrm{~h}$ & $0.45>0.417^{*}$ & $0.85>0.255^{*}$ & $0.35<0.4^{\#}$ \\
$18 \mathrm{~h}-48 \mathrm{~h}$ & $0.45>0.138^{*}$ & $0.5>0.344^{*}$ & $0.35<0.439^{\#}$ \\
$0 \mathrm{~h}-48 \mathrm{~h}$ & - & - & $0.7>0.344^{*}$ \\
\hline
\end{tabular}

This time, several statistically significant differences were obtained, though (as shown in the table) not in all cases. 
WÓJCIK A. and KRAJEWSKI A.: Mortality of wood destroying Anobiidae (Coleoptera) 147

\section{DISCUSSION}

The idea of using p-dichlorobenzene to accelerate the effect of a low oxygen atmosphere for controlling wood boring insects, studied by KIGAWA \& YAMANO (1996), probably came from the utilisation of this substance to disinfest fabrics attacked by insects (REGAN 1982, UnGeR 1988). As early as 1960, TANNERT (1960) advised the use of pdichlorobenzene for Anthrenus sp. control in entomological collections. However, no information was found regarding the susceptibility of Anobiidae to p-dichlorobenzene, apart from the results of the authors' own study performed in an aerobic atmosphere (WóJCIK et al. 2014).

The differences in mortality rates of both species for the same duration of the application of p-dichlorobenzene to nitrogen atmosphere fumigation were small and statistically insignificant, as already mentioned above (see Table 3 ). The authors could not then detect differences in mortality of Anobium punctatum and Ptilinus pectinicornis larvae by applying p-dichlorobenzene to low oxygen atmosphere fumigation, probably because of the relatively small number of larvae used in each variant of the experiment. The results cannot be related to literature data, as no papers were found that investigated the effectiveness of toxic gases in Anobium pectinicornis control. This insect species has been of marginal interest in this regard. Only one article was found that compared the susceptibility of larvae of both species to wood preservatives in a liquid state, which were, as a rule, alimentary or contact toxins. CYMOREK (1970) reported a greater susceptibility of Ptilinus pectinicornis larvae than of Anobium punctatum larvae to chlorinated hydrocarbons and older wood preservatives such as Combi-Basileum and Basileum SF. The results obtained in the present research seem to confirm CYMOREK's (1970) opinion of the relatively high susceptibility of Ptilinus pectinicornis larvae to toxic substances, although following the application of p-dichlorobenzene in an aerobic atmosphere at $20^{\circ} \mathrm{C}$, which is close to the optimal temperature of $22^{\circ} \mathrm{C}$ for Anobium punctatum, the differences were not clearly evident (WóJCIK et al. 2014). No information on the optimal temperature for Ptilinus pectinicornis could be found in the literature. Since the abundance of Ptilinus pectinicornis beetles peaks in June and July (DOMINIK \& STARZYK 2004), one can assume that this species is less vulnerable to overheating than Ptilinus pectinicornis. When $\mathrm{p}$ dichlorobenzene was used in an aerobic atmosphere, significant differences between the mortality rates of Anobium punctatum and Ptilinus pectinicornis larvae appeared only after the temperature had been raised to $30^{\circ} \mathrm{C}$, definitely unfavourable to Anobium punctatum (WÓJCIK et al. 2014). The larvae of both species of Anobiidae turned out to be far more susceptible to p-dichlorobenzene in an aerobic atmosphere than the much larger larvae of Tenebrio monitor LinNAEUS, 1758 (Coleoptera, Tenebrionidae) (WóJCIK \& KRAJEWSKI 2013). 
All larvae of both species died in the 48-hour variant of p-dichlorobenzene combined with nitrogen atmosphere fumigation at $20^{\circ} \mathrm{C}$. A statistically significant difference in the mortality of Ptilinus pectinicornis larvae as compared to the control was achieved already after 18 hours of application of p-dichlorobenzene to nitrogen medium fumigation. With regard to Anobium punctatum larvae, a statistically significant difference in mortality as compared to the control was achieved only after 48 hours of p-dichlorobenzene treatment in combination with nitrogen fumigation, although if the results were had been rounded up to the first decimal point, the difference could have been classified as significant in the earlier variant. Comparison of the experimental results on larval mortality after the application of p-dichlorobenzene to nitrogen atmosphere fumigation after 24 and 48 hours showed a statistically significant difference for both species.

As far as the application of p-dichlorobenzene to argon atmosphere fumigation is concerned, a statistically significant difference in mortality of Ptilinus pectinicornis, as compared to the control variant, was achieved only after 48 hours. What is more, the mortality rate of the test group did not reach the level of $100 \%$. In the research of TAVZES et al. (2001), argon and nitrogen were equally effective in destroying the mycelium of Coniophora puteana (SCHUM.: FR.) KARST. and Antrodia sinuosa (Fr.) KARST (in the original version: Antrodia vaillantii). However, some authors consider that argon fumigation results in the faster elimination of insects than nitrogen fumigation (VALENTIN 1993, KOESTLER 1995).

Many papers emphasise the slow disinfestation effect of low oxygen atmosphere, as compared to that of toxic gases (REICHMUTH et al. 1991, CONSIDINE et al. 1993, KoESTLER 1993, BROKERHOF 1999, BINKER et al. 2001, UNGER \& UNGER 1995, HASEGAWA 2001, KIGAWA et al. 2003). Because of this slowness, attempts have been made to accelerate the process by applying toxic substances such as p-dichlorobenzene (KIGAWA \& YAMANO 1996). However, research on the application of p-dichlorobenzene to nitrogen atmosphere fumigation at $20^{\circ} \mathrm{C}$, in the case of both Anobium punctatum and Ptilinus pectinicornis larvae, showed larval mortality to be not significantly quicker than with the application of p-dichlorobenzene to aerobic atmosphere fumigation, which was tested in earlier research (WóJCIK et al. 2014).

Owing to the incomplete set of duration variants of the experiment, as well as the limited number of larvae used in the tests (20-24 individuals), the results should be treated with caution and only as preliminary. Medium-sized larvae were used, placed outside the wood. The results may provide a basis for further research on the use of p-dichlorobenzene in low oxygen atmosphere fumigation against wood boring insects in wood blocks of various sizes.

However, such research will be much more difficult because of contradictory factors that may appear. Wood, being a porous material, will retain some oxygen, which may slow 
down the creation of a low oxygen atmosphere inside the wood. Oxygen is not easily removed from wood at a slightly negative pressure. Combined with the slow penetration of p-dichlorobenzene into the wood, this may slow down larval mortality. On the other hand, wood provides natural conditions for larvae, which lowers their stress levels and may encourage them to open their stigmae more often. This may increase their mortality following the application of p-dichlorobenzene to low oxygen fumigation. Such effects have been observed in research performed by staff of the Department of Wood Science and Protection, Warsaw University of Life Sciences, SGGW. The results of that research have not yet been published.

\section{CONCLUSIONS}

The following conclusions can be drawn from the results:

1. The tests did not reveal increased mortality of Anobium punctatum and Ptilinus pectinicornis larvae following the application of p-dichlorobenzene to low oxygen atmosphere fumigation at $20^{\circ} \mathrm{C}$ as compared to the results of applying p-dichlorobenzene in an aerobic atmosphere at the same temperature.

2. A $100 \%$ mortality of A. punctatum and P. pectinicornis larvae, placed outside the wood, was achieved after 48 hours of applying p-dichlorobenzene in combination with a nitrogen atmosphere at $20^{\circ} \mathrm{C}$. For this reason, it seems that 48 hours should be treated as the default duration for further research on the application of p-dichlorobenzene to a low oxygen atmosphere as a means of controlling wood boring Anobiidae inside wood

\section{REFERENCES}

BiNKER G., BINKER J., FRÖBA G. 2001. Innovative Stickstoffbegasungen in den von der Landesmuseen betreuten Einrichtungen in Bayern. [in:] B. REPP (ed.). Das Museumsdepot: Grundlagen Erfahrungen - Beispiele. Weltkunst-Verlag, München, 125-130.

BROKERHOF A.W. 1999. Low-oxygen treatment and solarisation of the Probota iconostasis: alternative pest control methods in the field. [in:] J. BRIDGELAND, J. BROWN (eds.). ICOM Committee for Conservation, 12 $2^{\text {th }}$ Triennial Meeting, Lyon, 29 August -3 September 1999. James \& James, London, 14-20.

Considine B., Danie V., Hanlon G., Maekawa S. 1993. Progress in project on the feasibility of using modified atmospheres for museum pests eradication: An overview. [in:] Papers presented at the Wooden Artifacts Group: specialty session, June 4, 1993, AIC annual meeting, Denver, Colorado. AIC, Wooden Artifacts Group, Washington D.C.

CyмoreK S. 1970. Über den „Gekämmten Nagekäfer“ Ptilinus pectinicornis (L.) (Col., Anobiidae) als Holzzerstörer, Zuchtobiekt und Testinsekt. Holz-Zentralblatt 96(66): 996. 
Dominik J., STARZYK J.R. 2004. Wood-destroying insects. PWRiL, Warszawa. (in Polish)

Hasegawa T. 2001. Control of pest problems in Ishikawa Prefectural Museum of History. [in:] Integrated pest management in Asia for meeting the Montreal Protocol. Proceedings of the $23^{\text {rd }}$ International Symposium on the Conservation and Restoration of Cultural Property, Tokyo, 27-29 September 1999. Tokyo National Research Institute of Cultural Properties, Tokyo, 153-164. (in Japanese)

Kigawa R., MiYazawa Y., MiURa S. 2003. Combined use of a simplified nitrogen generator and an oxygen absorber for efficient medium-scale low oxygen treatments for the eradication of museum pest insects. Hozon Kagaku 42: 71-77. (in Japanese)

Kigawa R., YAmano K. 1996. Accelerated mortality of Sitophilus zeamais and Japanese common museum pests by application of p-dichlorobenzene to the low oxygen atmosphere fumigation. Bunkazai hozon shūfuku gakkaishi: kobunkazai no kagaku 40: 24-34. (in Japanese)

KOESTLER R.J. 1993. Insect eradication using controlled atmospheres, and FTIR measurement for insect activity. [in:] J. BIDGLAND (ed.). Triennial meeting (10th), Washington, DC, 22-27 August 1993. Preprints. Volume II. ICOM, Paris, 882-886.

KoESTLER R.J. 1996. Anoxic treatment for insects control in panel paintings and frames with argon gas. [in:] K. BÉ (ed.). American Institute of Conservation Paintings Specialty Group, Postprints. AIC, Washington D.C., 61-72.

Koestler R.J., Mathews T.F. 1994. Application of anoxic treatment for insect control in manuscripts of the library of Megisti Laura, Mount Athos, Greece. [in:] Actes des Deuxièmes Internationales d'Études de l'ARSAG, Paris, 16 au 20 mai, 1994. Environnement et Conservation de l'Ecrit, de l'Image et du Son. Association pour la Recherche Scientific sur les Arts Graphiques, Paris, 59-62.

Koestler R.J., SARDJONo S., Koestler D.L. 2000. Detection of insect infestation in museum objects by carbon dioxide measurement using FTIR. International Biodeterioration and Biodegradation 46(4): 285-292.

KREHAN H. 2002. Eine globale Bedrohung. Schadorganismen in Verpackungsholz. Holz-Zentralblatt 101: 1150 .

REGAN 1982. Eradication of insects from wood textiles. Journal American Institute of Conservation 21(2): $1-14$

Reichmuth C., Unger A., Unger W. 1991. The use of nitrogen to control wood-destroying insects in works of art. Restauro 97(4): 246-251.

Rust M.K., Kennedy J.M. 1993. The Feasibility of Using Modified Atmospheres to Control Insect Pests in Museums. Internet: http://www.getty.edu/conservation/publications_resources/pdf publications/pdf/feasibility.pdf

TANNERT W. 1960. Zur Frage des Schutzes von Insektensammlungen gegen Anthrenus spec. (Coleopt.-Dermestidae). Anzeiger für Schädlingskunde 33(6): 87-92.

Tavzes C., Pohleven F., Koestler R.J. 2001. Effect of anoxic conditions on wood-decay fungi treated with argon or nitrogen. International Biodeterioration and Biodegradation 47(4): 225-231.

UNGER A. 1988. Holzkonservierung: Schutz und Festigung von Kulturgut aus Holz. VEB Fachbuchverlag, Leipzig. 
Unger A., Unger W. 1995. Die Bekämpfung tierischer und pilzlicher Holzschädlinge. [in:] E. EMMERLING (ed.). Holzschutz, Holzfestigung, Holzergänzung. Beiträge einer Fortbildungsveranstaltung des bayerisches Landesamtes für Denkmalpflege am 4 Mai 1992 in München. Tagungberiche Nr. 1. Bayerisches Landesamt für Denkmalpflege, München, 42-59.

VALENTIN N. 1990. Insect eradication in museums and archives by oxygen replacement, a pilot project. [in] K. GRIMSTAD (ed.). Proceedings of ICOM Committee for Conservation, $9^{\text {th }}$ triennial meeting, Dresden, Germany, 26-31 August 1990. Vol. II. ICOM, Paris, 821-823.

VALENTIN N. 1993. Comparative analysis of insect control by nitrogen, argon and carbon dioxide in museum, archive and herbarium collections. International Biodeterioration and Biodegradation 32(4): 263-278.

VAlentin N., Preusser F. 1990a. Insect control by inert gases in museums, archives and libraries, Restaurator 11(1): 22-33.

VALENTIN N., PREUSSER F. 1990b. Nitrogen for biodeterioration control on museum collections. [in:] G.C. Llewellyn, C.E. O’Rear (eds.). Biodeterioration Research. Plenum Press, New York, 511-523.

WÓJCIK A., KRAJEWSKi A. 2013. Effets du p-dichlorobenzène, à l'état gazeux, sur les différents stades de développement du Tenebrio molitor LinNAEus, 1758 (en milieu contenant de l'oxygène ou à faible teneur en oxygène). Entomologia Generalis 34(4): 269-277.

Wóscik A., KRAJewski A., RAdOMSKi A. 2014. Controlling of wood destroying Anobiidae using paradichlorobenzene in aerobic atmosphere. Wood Research 59(2): 219-225.

Received: 24 May 2017

Accepted: 11 January 2018 